\title{
MA GERÊNCIA PÚBLICA PARA OS NOVOS TEMPOS
}

\author{
Bernardo Kliksberg \\ (tradução de Marcelo Brito)
}

nfrentar os graves dilemas que afetam a América Latina recuer novas atitudes c uma cultura gerencial mais avançada no setor público e no privado. $O$ presente trabalho tem por finalidade construir um marco de referência sobre a nova gerência pública necessária e a situação c tendências observáveis neste campo.

Um confexto em mufação acelerada

\section{O}

tema da gerência tem se convertido claramente em uma das grandes questóes de nosso tempo a nível mundial. $A$ boa gerência é, hoje em dia, um dos recursos mais cobiçados que há no plancta. Um recurso que, sob qualquer ponto de vista, marca diferenças de competitividade, entre naçôes de um modo muito significativo. Trata-se de um recurso estratégico e, por outra parıe, escasso, não generalizado, nem no mundo, nem no interior das sociedades, inclusive das desenvolvidas.
U ma idéia fundamental em gerência atualmente é que o passado e um guia ruim, porque, devido as mudanças aceleradas, o presente difere do passado e o futuro diferira ainda mais do presente. Como trabalhar neste ambito de mudança dos tempos e de mudanças dos protagonistas? Desde já é necessário que as organizações públicas sofistiquem seus mecanismos de interpretação da realidade e suas capacidades de ajuste adaptativo a mesma.

Não há nenhuma atividade significativa da vida das sociedades modemas que não se desenvolva mediante organizaçōes. Gerenciar é iratar de alcançar as metas previstas mediante este cue é o modo de aglutinação de esforços caracteristico das sociedades humanas, nesia ćpoca histórica.

Gerenciar nesta década, a década de final de século, implica interrogantes muito diferentes dacueles que implicavam há pouco tempo, há mais de 10 anos, na década de 80. Gerenciar no setor 
público, por sua vez, implica, em nossa opinião, e vamos tratar de demonstrá-lo, interrogantes provavelmente ainda mais complexos que aqueles que significa esta atividade no campo econômico interrogantes muito particulares, ligados à características c objetivos das organizaçōes públicas.

Não é possivel realizar maiores análises sobre o tema da gerência, em geral e a pública $\mathrm{em}$ especial, nesta década de final de século, sem considerar o entorno no qual cla se desenvolve.

Gerenciar nos anos 90 é diferente de gerenciar nos anos 80 , porque estamos num entomo que tem-se modificado radicalmente. Um entomo histórico global, que está em processo acelerado de transformação, quase dia-a-dia. Iistão se produzindo revoluçōes absolutamente significativas em campos centrais da história que afetam o cotidiano, que afetam todas as organizaçöes, e que incidem fortemente nos parâmetros no qual se move qualquer tipo de gerência. Assim, estão se prơluzindo mudanças no campo tecnológico, que estão alterando fundamentalmente o que poderíamos denominar matriz. tecnológica das atividades centrais das sociedades organizadas. O impacto das revoluçōes tecnológicas em curso, em campos como, entre outros, a biotecnologia, a micro-cletrônica, a informática, a robótica, as comunicaçōes, está transformando decisivamente o processo de produção de bens e serviços, $\mathrm{cm}$ que se comercializam, em que se utilizam, e em que se consomem. Isstá modificando a paisagem das organizaçooes industriais, e de serviço, de toda indole, $\mathrm{cm}$ todo o plancta.

Por outro lado, ao mesmo tempo em que estão se produzindo estas profundas transformaçōes tecnológicas, que são em muitas áreas o resultado do que chamamos cm ciência e tecnologia, rupturas epistemologicas, ou seja, implicam em processos de crise, de toda uma maneira de compreender e atuar na realidade. Iistá ocorrendo um processo de transformaçōes geopolíticas, de enorme magnitude, profundidade e rapidez que está reordenando os modos básicos no qual se desenvolveu toda a história do século XX. Também em absoluta interação, com os dois planos anteriores, estão $\mathrm{cm}$ curso grandes transformaçôes geocconômicas $\mathrm{c}$ um reordenamen to das principais áreas de integração e influência econômica, a nível mundial.

Todo este conjunto de mudanças tem algumas características muito singulares que o diferenciam totalmente de outras épocas históricas, e que provavelmente só tcm semelhança, cm pouquíssimos momentos, em 
toda a história do gênero humano. Estão se produzindo, com uma tal rapidez, totalmente excepcional, que toma muito dificil sua metabolizaçāo individual.

Estas transformaçōes que afetam estratos muito profundos nos três planos - econômico, político e tecnológico - do que constituiam o modo de organização social básico, até pouco tempo, estāo se produzindo no marco do que hoje chamamos, denominando ao plancta, a grande aldeia. Uma situação de desenvolvimento histórico onde a inter-relação entre os países no âmbito do sistema econômico mundial e do sistema político mundial, é a mais estreita que já existiu na história. Onde os impactos significativos, em qualquer país central, têm repercussôes da maior significação $\mathrm{cm}$ todo o mundo c, além disso, as têm cm tempo real, transladam-se imediatamente, afetando aspectos fundamentais das abvidades sociais mais distantes.

Uma grande aldeia onde estāo se produzindo mudanças com uma velocidade acelerada e da maior profundidade. Os resultados imediatos destes processos históricos que estamos caracterizando muito sumariamente é o crescimento desde o princípio, até agora desconhecido, do que denominamos

atualmente: a complexidade.

Um mundo absolutamente interrelacionado com mudanças desta magnitude, c a esta velocidade, gera níveis de complexidade, nos problemas, e dentro deles nos problemas organizacionais e de gestão, inéditos até o momento. Por outra parte, um sinal fundamental desta complexidade, de final de século, é a incerteza; a maior parte das grandes transformaçōes, ocorridas nos úlıimos anos, no cenário histórico, nāo foram previstas pelos observatórios do futuro mais sofisticados que existem no mundo.

Os prognósticos que se manejavam apontavam para direçōes diversas. Penetramos num mundo que parece estar rodeado por uma área determinada por incertezas, que tem a ver com a complexidade.

Há uma nova ciência, que sungiu nos últimos anos, que se chama As Ciências da Instabilidade, tendo como pioneiro o Prêmio Nobel de Química, de 1978, Yllya Prygogine, um eminente pensador', que trabalha sobre a idéia de que o fenômeno básico, ao contrário dos que pensávamos em outras ćpocas históricas, nāo é a tendência ao equilibrio dos sistemas históricos, mas a tendência ao desequilíbrio e que

- Ver entre outros trabalhos, Ylya Prygogine. Tan sob una ilusión. Una exploración del caos al orden? Tusquets; Editores, Barcelona, 1988. 
sobre isso sabemos muito pouco. Issse é o mundo que temos que explorar, o mundo da complexidade, o das mudanças aceleradas, o mundo dos desequilibrios.

Introduzindo somente algumas idéias desta nova ciĉncia, Prygogine propóe que a maior parte das estruturas físicas, químicas, sociais, organizacionais, sāo estruturas dissipadoras, de final aberto. Nāo têm um desenlace pré-determinado. O que irá suceder nāo está prescrito de antcmāo.

Um dos maiores pensadores de nosso tempo, İdgar Morin, refutou tese (como a conhecida de Fukiyama) que aponta que a história terminou após a obtenção de hegemonia de uma potência e estamos ingressando na história entediada marcando que sucede o contrário. Morin disse que a incerteza se apoderou da história². Que, na realidade, tese como a antes mencionada confunde ofim da história com o fim do pós-modernismo. Morin ressalta que há revoluçōes nas três áreas mencionadas anteriormente, porém todas essas revoluçōes tem um estigma incerto, um estigma onde o único que está claro é a incerteza. Assim, Morin afirma que na área tecnológica os avanços são importantíssimos, mas ao mesmo tempo estamos destruindo parte do planeta, e a comprovação empirica sobre isso é convincente.

A Comissão 13runtland, das Naçōes Unidas, dirigida pelo primciro ministro da Norucga, testificou o dano fundamental que cstá produzindo no planeta em termos de degradaçāo do meio ambiente, o extermínio de espécimes, a toxicidade química de amplas zonas, a perfuraçāo da camada de ozônio cıc. Desıaca Morin que há um crescimento espetacular da tecnologia, mas um crescimento cego, sem um plano histórico definido. Por outra parte, na área política, produzem-sc revoluçōes políticas, profundas e melhoras das condiçóes de vida, de tempos muito positivos para a democracia. Pela possibilidade de que populaçōes inteiras totalmente separadas do modelo democrático possam começar a definir seus destinos. Porém, por outro lado, as chamadas potências hegemônicas constituem um ponto de referência muito confuso para o mundo, e se desencadearam gucras civis, processos de auto-clestruiçāo nacional, chauvinismos extremos c ondas de xenofobia e racismo.

Na área geo-econômica não estāo muito claras as perspectivas. um mundo que, ao mesmo tempo, teve avanços tecnológicos e está castigado pelas flutuaçóes cambiais, monctárias, recessāo, 
crisc profunda, fome, penúria c ć portador de iniquidades sociais inéditas na história.

Assim, o último relatório sobre a distribuição da riqueza mundial produzido pelas Naçōes Unidas informa que $20 \%$ da população são detentores de $82,7 \%$ do Produto Nacional Bruto, $81 \%$ do comércio mundial, $94,6 \%$ dos empréstimos internacionais, $80,5 \%$ do investimento interno. Aos demais $80 \%$ dla população só the restam as sobras. Por outra parte, a evolução é regressiva. Entre 1960 e 1990 as distancias dobraram.

A conclusão do filósofo é, como mencionamos, que a incertera se apoderou de história e, daqui por diante, o mundo que veremos não scrá o do fim da história, senão o de uma história muito aberta, a desenlaces que dependerão da ação humana e com sinais de complexidade e incertezas permanentes. Em igual direção o documento base de uma recente reuniāo do Clube de Roma destaca que somos mais ricos que nunca em conhecimentos, porém mais pobres cm sabedoria. Temos massas imensas de conhecimentos acumulados, porém temos uma menor capacidade para compreender o que está acontecendo do que cm outras épocas históricas anteriores".
Este é, em linhas absolutamente esquemáticas e gemis, o entorno no qual vai se desenvolver a ação concrela da gerência clas organizaçōes, no que resta desta década c nas próximas é esse entomo implica interrogantes diferentes totalmente aos da década dos anos 80. Deste entorno de complexidadc, em incertezas, e em mudança acelerada, se derivam para qualquer tipo de organizaçāo importante, pública ou privada, de qualquer setor, questões diárias para o gerente que são qualitativamente muito diferentes. No campo da gerência, como em muitos outros ramos atualmente do saber humano, a realidade é que está se delineando uma brecha entre o ritmo dos acontecimentos, a geração de todas estas mudanças, c as idéias que temos sobre os acontecimentos, ou seja, a sabedoria a que faziamos referência anteriormente. Não conhecemos o suficiente, e em muitos casos, o mínimo, para poder afrontar as mudanças que estão se dando.

O campo da gerência está numa crise muito profunda; falamos de uma mudança de paradigma. Isto implica que está se questionando todo o modo de pensar o problema, com todos os subcomponentes incluidos: princípios, hipóteses, arcabouços teóricos, tecnologias básicas etc. 
$\Delta \begin{aligned} & \text { seguir, abordaremos } \\ & \text { vários aspectos do que } \\ & \text { está acontecendo na }\end{aligned}$ gerência de alta relevância para a gerência pública. Entraremos no que vamos chamar novas demandas gerenciats para o setor públtco, tratando de por em evidência algumas das demandas mais significativas e estratégicas que se estão solicitando ao setor público.

Examinaremos como o modo de trabalhar na gerência tradicional é impotente para responder a essas novas demandas. Vamos abordar as limitaçōes do conhecimento que se maneja na gerência normalmente em nossas sociedades, os déficits do que estão ensinando nossas universidades, e muitas outras, inclusive de paises desenvolvidos para atender a essas demandas. Refletiremos sobre o que vamos chamar novas frontetras tecnologicas em gerêncta.

Procuraremos identificar como funcionam as organizaçōes mais avançadas do mundo, as que estão obtendo melhores resultados, tanto no setor público, como no setor privado, com ênfase no setor público.

Nāo pretendemos neste trabalho tratar estes aspectos de modo exaustivo, mas apenas explorálos, indicando uma agenda de problemas diferentes dos tradicionalmente suscitados.
Novas demandas para a gerência pública

I I novas demandas gerenciais para o setor público são muito amplas e cobrem um variado espectro. Tem a ver com o entomo ao que fizemos referência anteriormente, com a nova tecnologia, com os desenvolvimentos na área geopolítica, com as transformaçóes na área geoeconômica, com as necessidades prioritárias dos países da América Latina, como estabilizar a democracia, desenvolvimento econômico, competitividade, enfrentar a gravíssima situação social c ampliar a integração econômica.

Vamos a selecionar algumas demandas de uma agenda que pode ser muito mais ampla, que podem ser significativas e que deveriam em nossa opiniāo serem consideradas cuidadosamente por alguém que trabalha com responsabilidades diretivas no setor público.

O primeiro grupo de demandas observáveis é aquele que se relaciona com o perfil do Iistado. Para qual tipo de Estado? É uma discussão de fundo que emoldura os propósitos de melhoria da eficiência, em organizaçōes do setor público, em qualquer dimensão. Existe um amplo 
debate aberto a nivel internacional a respeito e que tem passado por distintas etapas.

Parecerá que a discussāo está começando a tomar um curso distinto ao de épocas anteriores. As teses polares sobre o Estado, ou seja, a tese de outra ćpoca do Estado intervindo como protagonista absolutamente central, ocupando todos os espaços e resolvendo todos os problemas, $\mathrm{c}$ a tese oposta $\mathrm{cm}$ voga, $\mathrm{cm}$ alguns países, $\mathrm{cm}$ alguns âmbitos, que ć a absoluta ausência de toda atividade estatal, o absoluto distanciamento do listado de toda atividade significativa, parecem as dois estarem em crise.

As evidências indicam que $\mathrm{ncm}$ uma nem outra resolvem os problemas concretos da vida cotidiana e muito menos os que sugere esta história dominada pela incerteza, de que nos fala I:dgar Morin.

Há múltiplas aproximações nessa direção. Por exemplo: na revista empresarial Business Weck um prestigioso economista assinala que uma das razóes das grandes dificuldades competitivas dos Istados Unidos são os equívocos sobre o papel do Estado.

Enquanto o Japão e uma séric de países europeus mantiveram funçōes estatais razoáveis $\mathrm{e}$ ativas em suas sociedades, servindo de base ao desenvolvimento, a competitividade, e ao progresso da empresa privada, nos Estados Unidos, diz o trabalho, a influencia de um neoliberalismo radical tem levado a debilitar funçōes, que sāo estratégicas, para que a empresa privada possa ser competitiva.

O título do artigo é: "Why business needs a stronger and wiseruncle Sam" (Por que a empresa privada dos Isstados Unidos necessita um Estado mais forte e mais inteligente) 4 .

Ile toma quatro áreas onde demonstra isso de um modo muito significativo. Examina a área financeira e assinala que enquanto nos Estados Unidos se impôs no Reaganomics c scus seguidores a idéia de que o sistema financeiro devia ser totalmente desregulado, em outros países de economia ocidental se manteve um acompanhamento cuidadoso do sistema financciro.

Quem pagou a desregulação no sistema financeiro dos Istados Unidos? Os contribuintes, que tiveram que contribuir com quinhentos bilhōes de dólares para dissolver o desfalque maciço das entidades de poupança c empréstimo.

- Robert Kuttner. Why Business needs a stronger and wiser-uncle Sam. Business Weck. 03 de junho de 1991. 
U ma intervençāo muito mais ativa do listado nesse campo a nível regulatório e de supervisāo, assinala o artigo, teria tido custos distintos para o contribuinte; poliam ter sido aplicadas politicas preventivas.

Assinala em outro campo totalmente distinto, o da saúde, como o custo final de sistemas iguais aos de diversos países curopeus com uma cobertura social ampla de saúde, e muito mais baixo (jue o custo de um sistema desregulado e totalmente aberto ao mercado, como o americano, porém onde o Fstado finalmente tem que intervir para subsidiar aos numerosos setores que ficam desprotegiclos, e para desnivelar os desequilibrios que se produzem.

I:m terceiro lugar assinala o caso do pleitismo nas sociedades, onde o Estado prescinde de tokla atividade. Ao retirar-se o Estado cessam, de fato, as funçōes de arbitragem que está levando a cabo, numa quantidade de áreas da cconomia, aumentando o númcro de disputas jurídicas. O pleitismo nos Estados Unidos é muito maior que o de diversas sociedades na conomia ocidental, onde o Estado tem uma intervenção regulatória muito mais ativa, e isso tcm custos supérfluos (em tribunais, tempo, etc.) importantes para a cconomia.

O quarto exemplo que menciona é o de formação de māo-de-obra para a inclústria, que ć um campo fundamental. Ali a distância entre - modelo japonês e o modelo americano é muito ampla, e se considera que é um dos fatores que pesam em maléria de competitividade. De um lado, uma política estatal dura, planificada e absolutamente forte para preparar os quadros para a indústria adotada pelo Isstado, que leva a que atualmente $90 \%$ dos japoneses em idade de ensino secundário estão estudando no colćgio secundário; c a mão-deobra sabe matemática c lógica, pelo tipo de programas de estudo.

Nos Istados Unidos, ao contrário, está se produzindo déficits muito importantes em cducação e ali há outra brecha de competitividade relevante. Istce ć um exemplo de muitas outras novas investigaçōes que há nesta linha e que vem tomando força crescentes. A idćia é que tem que haver um Iistado com outras

, Entre elas o economista americano Walter Rusecl Mecd, destaca que a superioridade competitiva de alguns paises europeus e Japáo sobre USA ce Grä liretanha. se deve ao liberalismo dogmálico destes últinos frente as politicas economicas dos anteriores que "desenvolveram estratégias industriais nas quais o Estado no renega seu papel orientador da atividade cconómica". Escreve Meed (Los Angeles TimeClarin, 22/2/92): "Desde alguns anos resultava claro para os observadores agudos que as coisas iam mal com o Grande Experimento da década dos anos 80. A diminuicio dos niveis de 
funções distintas às décadas anteriores, nāo paternalistas, não expandido cm áreas da economia que the são alheias totalmente, porém um Estado inteligente, muito mais forte em funçôes cstratćgicas scm as quais não há competitividade, nem se solucionam problemas fundamentais no conjunto da sociedade.

Um segundo tipo de demandas para a gerência pública tem a ver com o como lidar com a complexidade e com a incerteja. Uma coisa e gerenciar num meio como o dos anos 60,70, inclusive o dos anos 80; c outra é faxê-lo no meio que terminamos de descrever, na aldeia global submergida no ultracambio.

A gerência cotidiana deve trabalhar hoje nesse entomo, tipo aldeia global onde tudo se interrelaciona com tudo. As oscilaçōes cm Wall Street têm efeitos imediatos no Nikei japonês, repercussōes na bolsa de Madri e impactos sobre o sistema financeiro a nível intemacional. $O$ mesmo acontece com o mercado petroleiro ou com outras áreas estratégicas da economia.
Em gerência estratégica chamamos isto de gerenciar num mundo de indiscretos $\mathrm{cm}$ um mundo onde no contexto do gerente de uma onganizaçâo de alguma significação, incidem as variáveis fundamentais do entorno histórico-global. O gerente público que não leva $\mathrm{em}$ conta cuidadosamente o contexto será surpreendido a qualquer momento e pode equivocar-se de uma mancira muilo grave. Como gerenciar num mundo de indiscretos?

Por outra parte, como gerenciar num mundo onde as características do entomo determinam que se tenha virtualmente caído $\mathrm{cm}$ sua integridade o marco de referência com o que os gerentes mancjavam o problema do tempo?

Isto significa o seguinte: tanto nas organizaçoóes privadas como públicas acostumava-se utilizar o passado como guia. Assim, as cifras orçamentarias se estimam a partir de plus ou adicionais às cifras orçamentárias anteriores.

No campo da empresa privada as cifras de marketing se projetam

poupança desregulados e os bancos, o clima de escándalo e pirataria dos mercados financeiros, a constante caida dos salários reais e, talvez o mais preocupante, o itento crescimento da produtividade eram indicadores de que algo andava mal. Os que seguiam acreditando permaneceram impávidos. Nảo viria nenhuma recessảo, diziam. Iogo, quando veio, disscram que seria por pouco tempo. Apenas estava chegando quando já diziam que já havia terminado. Agora com a recessào que se prolonga e as eleiçōes a vista, se ouvem ruídos de pánico no templo". Por sua parte o Prémio Nobel Paul Samuelson sugeriu do Presidente Clinton entre outros aspectos programbs públicos anti-recessivos e favorecer a formaça de capital humano (Clarin, 17,01,93). 
tendo em conta os posicionamentos históricos etc.

Uma idéia fundamental em gerência atualmente é que o passado ć um guia ruim, porque, devido às mudanças accleradas, $o$ presente difere do passado $\mathrm{e} o$ futuro diferirá ainda mais do presente. Qualquer destas mudanças espetaculares no campo tecnológico, por exemplo, tem impactos de grande transcendência a nível econômico c organivacional.

Sc o passado, numa época de transformaçōes desta magnitude, não é guia, também há dificuldades muito sérias com o presente c com o futuro. O futuro nāo está ali, nem aos 10 anos, nem aos 15 anos, nem a nenhum dos estimados pela planificação que se mancjava normalmente no mundo. $O$ futuro está aqui mesmo; o futuro se aproximou totalmente do presente, e as fronteiras sāo muito confusas. Como trabalhar neste âmbito de mudança dos tempos e de mudança dos protagonistas, como assinalamos anteriormente cm um mundo de indiscretos? Desde já, necessita-se que as organizaçōes públicas sofistiquem muito mais scus mecanismos de interpretação da realidade e suas capacidades de ajuste adaptativo a mesma. Uma tendência muito importante dos principais organismos que preparam gerentes a nível mundial $\mathrm{c}$ a idéia de que um dos trabalhos centrais do gerente aplicável a qualquer tipo de organizaçōes, e a de que cle é um legitimador da realidade. O gerente dá, à sua organização, uma visāo do que está ocorrendo no entorno c portanto como se deveria orientar a organizaçāo, tendo. cm conta as tendências em curso.

Isle legitima para o interior da organização uma determinada interpretaçāo da realidade. Se equivoca-se, toda a organização ć induzida a graves crros. E fundamental capacitar o gerente público para que faça um bom irabaIho de legitimação da realidade, $c$ isso implica, por exemplo, numa preparação de primeira qualidade para entender a geocconômica c a geopolítica mundial.

6) necessário reforçar sua formação $\mathrm{cm}$ instrumentos de economia, sociologia, antropologia, demografia, história e de filosofia, para entender o que está acontecendo no en tomo.

Primeiro, conformamos demandas para uma gerência pública para um Estado inteligente. Segundo, demandas para uma gerência muito mais sofisticada para enfrentar a complexidade e incerteza. 'Ierceiro, há demandas dirigidas à melhoria radical da qualidade dos serviços que se prestam ao cidadâo. O tema não é simples e começa ao 
perguntarmos como o faz Christopher Pollit: Que é qualidade dos serviços? Suas indagações de campo o levam a conclusão de que há diferentes interpretaçōes de qualidade segundo os atores consultados ${ }^{6}$.

Pollit consultou a quatro setores importantes no assunto, que the deram visōes distintas.

Ele tratou de ver o que era mclhoria da qualidade dos serviços para os líderes políticos; eles têm determinada visão do que é melhor para o cidadāo, que tem a ver com suas metas, com seu próprio tempo político etc.

Segundo, consultou ao alto nivel de grandes organizaçōes públicas que, tambćm, tcm detcrminada visão distinta da dos políticos e que coincide com seus próprios interesses de sobrevivência e desenvolvimento no cargo $c$ de êxito organizacional.

Terceiro, os profissionais que prestam serviços, os especialistas nas áreas de saúde, educação, habitação e que têm uma visão do que é melhorar a vida do cidadão, que tem a ver, conforme scus egos profissionais, com seus pontos de visıa, a partir das práticas usuais dc suas disciplinas.
Finalmente, consultou os cidadãos sobre como percebiam os esforços de melhoria na qualidade dos serviços, e resultou que uma quantidade muito importante de casos sobre o que os cidadãos querem como melhoria da qualidade dos serviços corresponde a percepçōes diversas da dos três setores anteriores.

Sua agenda sobre o que é melhorar a vida, a ênfase que é dada, é distinta da cle outros setores. As demandas, neste caso a gerência pública são, desde já, o objetivo de se ter em conta o que os cidadãos pensam sobre o que deve melhorar. Por exemplo, os cidadãos pensam que um tema absolutamente importante é que eles escrevam, tudo o que se thes comunica, desde os anúncios nos jornais até os formulários, na linguagem deles e não na linguagem dos funcionários. E um tema importante, porque uma proporção importante não entende a outra linguagem. Os cidadãos têm a pretensão de que as organizaçōes funcionem $\mathrm{cm}$ horários aos que eles realmente possam acudir, que não são os horários normalmente dispostos para eles e que, pelo contrário, coincidem com seus horários de trabalho, como ainda, que as repartiçōes estejam em lugares aos quais eles tenham fácil acesso e assim sucessivamente. Fstas são

- Christopher Pollit. The politics ofquality assesment in profesionally, provided public services. Em B. Kliksberg (comp.) Pobreza. Un Tema Irnpostergabb. Nuevas respuestas a nivel mundial. (Fondo de Cultura Economica, 1993). 
algumas das coisas que significam a melhoria da qualidade para 0 ciđadâo.

O quarto tipo de demandas significativas para a gerência pública são as que têm a ver com a democratização de nossas sociedades. As socicdades exigem mudanças onganizacionais, que matcrializem a democratização cm fatos. Nenhuma sociedade de nosso tempo, situada $\mathrm{em}$ qualquer parte, conforma-se atualmente cm votar uma vez cada tantos anos para eleger autoridades. $\Lambda$ pressão é por participação muito mais cotidiana $\mathrm{c}$ em assuntos relevantes. Isto significa uma série de demandas por mudanças organizacionais, no senticlo de abrir a participaçāo cidadā, através de modelos, que realmente a facilitem, de melhorar os mecanismos de transparência $\mathrm{cm}$ tudo o que ć informação dos atos públicos para a cidadania, de ingressar seriamente no controle social. Do mesmo modo, descentralizar o Estado em espaços muitíssimo mais demarcados c próximos aos cidadão que the permitam controlar a gestão, de modo direto. Desde já, implica no qual, em países como Espanha, constitui uma experiência fundamental da democracia, como a descentralização do listado, o fortalecimento dos municipios e das regiōes.
Há um quinto grupo de demandas que tem a ver com um objetivo, que as Naçôes Unidas denominou de progresso $\mathrm{cm}$ termos de desenvolvimento humano, das socicdades. $O$ Programa das Na- çōes Unidas para o Desenvolvimento (PNUD) vem publicando uma série de volumes que se cha- mam Relatórios sobre Desenvolvimento Humano, c são o produto de um grande esforço de investigação.

Nestas obras se questiona, muito diretamente, a visāo puramente economicista do desenvolvimento. Analisa-se o que vem ocorrendo com 160 países do mundo durante os últimos trinta anos, e se estabelece, com uma ampla base de dados quantitativos, que um país pode alcançar progressos no campo cconômico, mas que ao mesmo tempo pode estar retrocedendo no campo do desenvolvimento humano.

Propōe-se que o desenvolvimento humano é a meta final. Tratase de medir sistematicamente pela primeira vez, provavelmente - o desenvolvimento humano. Na primeira versão deste vasto trabalho, de abrangência mundial, aferiu-se o desenvolvimento humano com três indicadores: esperança de vida, taxa de escolaridade e produto bruto per capita.

7 - Programa das Naçōes Unidas para o Desenvolvimento. Descruvolvinkento Humano. Infornkes 1990, 1991, 1992. 
ponderado pela distribuição de renda.

İm uma seguncia versão, ampliou-se a lista para onze indicadores, implicando indicadores de liberdade, de democracia, de utilizaçâo de bens culturais etc. A icléia é que o objetivo final das sociedades é, em resumo, que a populaçâo viva mais anos e com maior qualidade, e a isso, muito sinteticamente, se chama desenvolvimento humano. $O$ desenvolvimento econômico é muito imprescindivel, absolutamente ninguém discute isto, porém deveria estar a serviço do objetivo último.

Ao avaliar e medir todos os paises do mundo, com os indicadores de desenvolvimento humano, o estudo indicou que os primeiros na tabela são os países nórdicos (Sućcia, Dinamarca, Noruega c Finlândia), alguns países da Iúropa Ocidental c o Canadá.

Quais são as chaves, segundo este estudo, pelas quais umas socicdades obtém desenvolvimento humano $c$ outras não? Mencionam-sc entre clas uma estrutura cqüitativa de distribuição de renda. Isste é um ponto absolutamente fundamental, do contrário os progressos cconômicos não se irradiam para a sociedade, não se cumpre o mecanismo de difusão dos progressos.
Destaca-se uma politica de cobertura social, agressiva. İm todos os casos, a indicação é a de que o listado cumpre uma função muito ativa nesse campo a nível internacional naqueles paises onde o desenvolvimento humano é importante.

Por outra parte, ressalta-se especialmente que a política cconômica deve articular-se com a política de desenvolvimento humano. Coloca-se em questionamento o conceito da teoria del derrame. Segundo cla, o progresso econômico se disseminaria somente no âmbito do conjunto da sociedade. Os documentos demonstram que isto não é assim e sem uma articulação estreita entre a política econômica c a política de desenvolvimento humano não há progresso no conjunto da sociedade. Um sistema fiscal progressivo redunda em um dos instrumentos importantes $\mathrm{em}$ vários destes aspectos.

Deste tipo de análise surgem novas demandas para a gerência do sctor público. Se o objetivo ultimo se propōe em termos de desenvolvimento humano das sociedades, a questão é como lograr orientar a gerência nessa direção, o que implica tarefas como propiciar a autoorganivaçāo das comunidades, a participação ativa das mesmas c a sociedade, a descentralivação dos 
programas sociais, apoiar as ONG's etc ${ }^{8}$. Isto envolve complexas funçōes para a gerência pública.

A especificidade da gerência pública

odas estas demandas e outras identificáveis delineiam a gerência pública atual como um campo de alta especificidade técnica. Trata-se de gerenciar organizaçōes públicas, que tem que forjar um Estado Inteligente, fazer frente à complexidade e a incerteza, melhorar a qualidade dos serviços aos cidadãos c procurar o desenvolvimento humano ao mesmo tempo que o econômico.

Realizar tudo isto ao mesmo tempo que cooperar com o aperfeiçoamento dos mecanismos democráticos, compatibilizando o que se faça com mais transparência, mais controle social, mais participação cidadã, implica numa problemática gerencial que, em seu conjunto, é distinta das problemáticas gerenciais de outros setores da economia. Sendo válidas totalmente as problemáticas de outros setores, cada uma delas tem sua propria especificidade. Gerenciar organi- zações públicas nestes tempos vindouros tem diferenças significativas em gerenciar onganizaçōes privadas e, de outra ordem, em termos de dilemas gerenciais, opções, problemas de compatibilização de objetivos, de restriçōes c possibilidades, enquanto a eleição de meios. Isto exige respostas tecnológicas gerenciais que são específicas.

Por outro lado, investigar sobre gerência pública é trabalhar na formação de gerentes públicos são requisitos essenciais para poder ser minimamente eficaz no setor público.

Os intentos de transladar mecanicamente tecnologias de outros setores ao setor público tem demonstrado sérias dificuldades. Há sobre isso múltiplas evidências a nivel internacional.

Por sua vez, dentro do setor público é possível falar atualmente, e há linhas muito amplas de trabalho nessa direção, de gerências especializadas com forte impacto diferencial. Os problemas variam segundo se trate de gerência econômica, de gerência social etc.

Por isto, um dos mais prestigiosos centros de formação pública do mundo, a John Kennedy

- O autor trata detalhadamente o tema da gerència social em suas obras: Bernardo Kliksberg(comp.) ¿Como Enfrentar la Pobreza? Aportes para la accion. Grupo Editor Latino-americano, 2 Edicion, 1993, e em B. Kliksberg (comp.) Pobreza. Un Tema Impostergable. Fondo de Cultura Economica de México, 1993. 
School, da Universidade de Harvard, destaca o caráter particular da gerência pública assinalando:

Lim contraste com a educação para os negóctos, por exemplo, o treinamento para a vida pública requer uma profunda compreensão do contexto politico e constitucional da gestão governamental onde a autoridade $e$ o poder se encontram amplamente difundidos. Enquanto ambos, a empresa privada e o Governo, demandam gerência eficiente, os instrumentos utilizados por um executivo de negócios são com freqüência as restriçōes nas quais o gerente público deve trabalbar. $O$ executivo de negócios pode usualmente redefinir as metas da organização, modificar sua estrutura e mudar seu pessoal. Os gerentes públicos, por outro lado, devem ter babilidades que Ihes permitam operar dentro das metas fixadas por lei, uma estrutura organizacional controlada pelo sistema juridico, funcionários protegidos pelo sistema do serviço civil $e$ a constante $e$ penetrante pressão da politica?. Na mesina direção ressalta I.'Institut de Management Public de Paris, que a base da noção de gerência pública e o "reconbeci- mento das especificidades das organizaçóes públicas"'.

\section{Crise do paradigma gerencial tradicional}

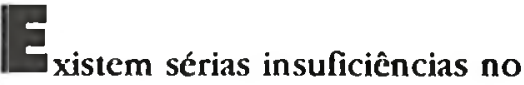
conhecimento científicotecnológico manejado no campo da gerência na regiāo, cm geral, para fazer frente a estas novas demandas gerenciais.

O paradigma gerencial no qual se formaram as geraçōes nas últimas décadas, ou seja, o modelo dominante de pensamento em gerência, está cm crise.

No modelo dominante, a idéia básica é a de que gerenciar bem é modelar uma organização seguindo as linhas do modelo weberiano, ou dos fundadores da ciĉncia da administração, Taylor e Fayol, c seus seguidores modernos. Uma boa organizaçâo é a que tem um onganograma detalhado, maximiza a divisão do trabalho, planeja todas as funçōes que a integram, conta com descrição de cargos, manuais de tarefas, procedimentos, circuitos.

Supóe-se que se arma toda a estrutura formal da organização, planifica-se cuidadosamente e se aplicam determinados princípios

\footnotetext{
9 - John F. Kennedy School of Govemrnent, Harvard University, 1987/1988.

10 - L.'Institut de Managernent Public. CESMAP, Paris, 1984,
} 
de administração, como unidlade de comando, âmbito de controle restrito ctc, tudo passa a funcionar otimamente.

$\mathrm{Na}$ prática, isto não garante o rendimen to efetivo. Há uma vasta literatura que o demonstra terminantemente. Entre muitas obras Peters e Waterman, Lin busca de la excelência (Editorial Norma) conclui de múltiplas experiências de consultorias privadas, que aplicando muito bem o desenho c o plancjamento formal só se influi sobre uma porcentagem muito reduzida da produtividade organizacional final. Esta, em sua maior parte, tem a ver com outras questōes, muito mais profundas na vida da organização.

Isso não quer dizer que se esteja assinalando que há que renunciar a onganização formal. O que estamos expondo é que isso é nada mais que um instrumento de alcances limitados, que há que ir muito mais além para poder ter resultados efetivos.

Por outra parte, no contexto de complexidade e incerteza descrito, que ć a condição normal na qual se vive na ação gerencial a ênfase na onganização formal, muito própria de nossas culturas organizacionais da região, e a conseqüente concentração de esforços $\mathrm{cm}$ que isso funcione assim, pode ser altamente disfuncional. İm situações onde tudo muda permanentemente, uma recomendação elementar e maximizar a flexibilidade da organizaçāo, dotá-la das melhores condiçôes de adaptabilidade.

Se dada ênfase a estruturas fixas, permanentes, rigidas, se está indo no sentido oposto. A capacidade de reagir ante situaçóes de mudança tenderá a diminuir seriamente.

Algumas das disfuncionalidades que, com mente visionária, propôs Robert Merton há várias décadlas, tem plena vigência atualmente. Merton assinalou que as organizaçōes que tendiam a cumprir estritamente o modelo burocrático de Weber, e davam ênfase nisso, produziam um fenômeno que chamou de incapacidade disciplinada ao transferir todo o valor ao cumprimento das normas em lugar das metas. "Iudo muito disciplinado e incapaz.

Se força-se à formalidade, as organizaçōes, num tempo de transformaçōes muito rápidas, tendem-se a gerar uma soma de incapacidade disciplinada muito alta. A onganização formal não pode responder a proliferaçāo de variedade própria das realidades presentes ${ }^{11}$.

11 - Pode se encontrar uma critica detalhada das versóes modernas do formalismo administrativo em B. Kliksberg. El Pensamiento Organizativo De los dogmas a un nuevo tiempo gerencial. $12^{2}$ Ediçào, Editorial Tesis. NORMA, 1992. 
nclusive instrumentos muito mais sofisticados, como os do planejamento estratégico, têm demonstrado sérias limitaçōes ao operar em âmbitos de complexidade e incerteza.

Henry Mintaberg, da Universidade Mc Gill do Canadá, disse que há um erro básico nisto, que ć a dissociaçāo da planificaçāo da açāo. Se alguém se senta, planifica e depois vem o processo, de implementação, a realidade c tão fluida c rápida que fracassará. $O$ único que vale é aproximar estreitamente planificação c ação, e levar adiante um processo continuo de aprendizagem, retroalimentar em tempo real o que está acontecendo. Não se trata de deixar de planificar, senão que a planificação tem que acelerarse totalmente. 'Iudo o que é formal está condenado a ter dificuldades muito sérias frente à mutação contínua da realidade que estamos indicando ${ }^{12}$.

Uma gerência pública conduzida pelo paradigma tradicional será necessariamente impotente para contestar com eficiência as novas demandas antes expostas: Istado inteligente, complexidade, qualidade dos serviços, desenvolvimento humano. Que tipo de gerência se necessita? Para visualìa-la é necessário ir mais além do paradigma tradicional e introduzir-se no novo paradigma que se está conformando em gerência a nivel internacional $\mathbf{c}$ que tendem a aplicar-se nas organizações públicas e privadas mais avançadas.

\section{Novas fronteiras fecnológicas em gerência}

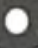

que é que estão fazendo as onganivaçöes que melhor funcionam no mundo? Entre os principais campos onde inovam se destacam:

\section{1 - 0 conceito renovado de gerência de excelência}

Como ser um gerente de excelência? Na Universidade de Harvard, John Kotter, titular da cátedra de comportamento organivacional, realizou uma amostragem de gerentes bem sucedidos nos Istados Unidos ${ }^{13}$. Seguiu estes gerentes durante vários anos tratando de determinar que faxem os gerentes de excelência com seu tempo.

O resultado foi que mais de $90 \%$ de seu tempo estava dedicado a uma atividade que se chama conversar. $\mathrm{O}$ gerente de excelência se dedica

12 - Henry Mintaberg. The designs school: reconsidering the basic prenises of strategic managenkent. Strategk Management dournal. MarcoAbril, 19\%).

13 - John Kolter. What effective general managers really do? Harvard Business Review. nov-dec. 1982. 
fundamentalmente a conversar, ao contrário do que se ensina na américa ibérica com muita freqüência nos cursos sobre o uso do tempo, onde o gerente capaz seria o que está encerrado no escritório protegido por secretarias, que não deixam passar ninguém, e só fala com seu staff imediato, ou está todo o dia pensando no futuro. O gerente de excelência é um exímio conversador, que dialoga com todo tipo de gente, de todas as linhas da organização, como também de fora dela, que sai permanentemente do seu local de trabalho. Conversa de tal modo onde haja mangem de tempo ocioso. Faz muitas perguntas. Nāo tem sua agenda pré-planificada por meses, nem por anos. Sua agenda é profundamente reativa. Analisando os contatos que realiza, são na sua grande maioria contatos que surgem a instâncias das realidades imediatas.

Por que alguém se cledica a conversar do modo descrito? E altamente eficiente? Segundo Kotler e o grupo de Harvard, com isto executa de modo satisfatório aquilo que é crucial para que exista um bom gerente no mundo atual.

Primeiro, através das conversaçōes, logra armar a agenda estratégica de decisōes. Logra identificar os problemas que são realmente cruciais para o futuro da organivação. Isses não se obtém através da informação da hicrarquia burocrática, senão que os consegue fora dela, conversando com as pessoas, de diferentes visōes, muitas vezes contraditórias, que lhe proporcionam informação c análises frescas.

Segundo, através das conversaçōes, logra armar o que se chama de rede de contatos. Nas sociedades atuais as coisas funcionam se existe uma rede de contatos. O gerente, através dessas conversaçōes, desenvolve processos de negociação, com protagonistas muito variados, para armar a rede de contatos na qual se apoiará a execuçāo de suas decisōes.

Na mesma direção, uma renomada consultora gerencial, Stephanie Winston, cujos livros, "Getting organized" c "The organized executive", venderam um milhāo de exemplares, esteve interrogando a 48 Ceo's (máximos exccutivos) de grandes companhias que apenas 2 horas de sua jomada de trabalho, de 9 a 10 horas, consistiam em contatos préplanificados (agendados). $\mathrm{O}$ restante eram respostas sobre o momento. Ixplica que os maiores executivos do país vão para seus escritórios pela manbai com apenas uma idéia vaga do que o dia lbe proporcionara ${ }^{14}$.

". The Ceo's Secret Managulg Time. Fortune. 01 de junho de 1992. 


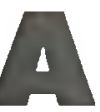

diretora da Harvard Business Review, Rossabeth Moss Kantor, realizou uma pesquisa sobre gerentes de excelência por sua vez, todas estas pesquisas coincidem com outras que se realiyaram na França $c$ na Inglaterra $c$ indica que analisando-o na prática, a tarefa de um gerente de excelência e fazer bem os quatro efes ${ }^{15}$.

Primeiro, focus, isto é, focalizar o que é a agenda estratégica, lograr identificar quais são realmente os problemas criticos. Não se perde, c hoje as possibilidades de perder-se são muito maiores que antes, pela massa de informação que pode fazer chegar a seu escritório.

Segundo, fast, quer dizer, a decisão tem que ser rápida. Não há tempo.

Há que acabar, assinala, com as organizaçôes tipo elevador, onde há um elevador bierárquico como estrutura básica. 'l'udo tem que subir pelo elevador respeitando cuidadosamente todas as hierarquias, as ordens tem que baixar pelo elevador $c$ os informes tem que subir pelo elevador e os contatos horizontais estão proscritos ou são mal vistos na organização.
Com a organização tipo elevador nāo se pode fazer fast, não se pode responder as necessidades de adaptabilidade, que têm o tempo no qual vivemos. Há que buscar outros modelos organizacionais.

'Terceiro efe, flexibility, maximizar a flexibilidade da organização para responder. Isto implica entre outros aspectos, fluidificar os contatos horizontais nas organizaçōes, que são os que permitem diagnosticar e resolver os problemas com rapidez.

$O$ último efe é friendly, que quer dizer negociando, inter-relacionando-se, não operando através de uma mera imposição autocrática.

\section{2 - Por uma renovação dos modelos organizacionais}

O que está acontecendo $\mathrm{cm}$ matéria de desenhos organizacionais em organizaçôes avançadas?

A London School of Business Administrations realizou uma pesquisa sobre modelos organizacionais atuais. Concluiu que há quatro modelos predominantes. Essquematizandos, um deles é o modelo Zeus, onde há um chefe que centraliza tudo na organização. Este alguém que tem todo

13 - Rossabeth Moss Kantor. Tendendas Generabs en los Estados Unidos. Investigacion y Gerenda. Caracas, n $34,1991$. 
- poder o exerce de forma autocrática. 'Iudo tem que passar por Zeus.

Zeus podia existir na década de sessenta, com um mundo muito mais estável, mas não na década atual. Não há possibilidade de nenhum ser humano que possa ser eficiente por si mesmo diante da complexidade.

Segundo, o modelo Apolo, clássico das organizaçóes nos Estados Unidos, durante décadas anteriores. Aqui se incita ao máximo a competitividade, entre os niveis diretivos da organizaçāo, que lutam uns contra os outros, para que sobressaiam os triunfadores, os apolos. Isto leva a uma soma de destrutibilidade no interior da organização, de confrontaçōes intensas. Para sobreviver num mundo de complexidade $\mathrm{e}$ incerteza, e altíssima competitividade, a organização tcm que promover, pelo contrário, o espírito de cooperaçāo.

Terceiro, o modelo Dionisius, que é uma variante do $\Lambda$ polo. Exalta o narcisismo pessoal nas organivaçōes, todo tipo de gratificaçōes individuais, a alcançar o êxito individual por todas as vias.
Novamente tem muito das contra-indicaçōes de Apolo cm termos de incitação a competitividade intema ${ }^{16}$.

O último modelo que destacam como avançado é Atenas. Referese a organivaçōes altamente descentralizadas em lugar das macro-organizaçōes, indicação atualmente muito generalizada.

Por outro lado, refere-se ao estimulo à autofixação de metas, pelos diferentes grupos descentralizados, estimular o trabalho, a partir de condiçöes autônomas, de cada um dos grupos e num marco de alta deliberação para poder entender o que se passa na realidade.

Na mesma direção deste trabalho, um pesquisador importante de Harvard, o Prof. Willis Harman disse que gerência se entendia tradicionalmente como a direção de recursos humanos, materiais $c$ financeiros para determinado objetivo.

Hoje, na realidade, corresponderia retraduzir totalmente o conccito. Gerência não é a direção para determinados objetivos, senão facilitar as condiçōes

16 - Una pesquisa sobre uma ampla amostra de gerentes americanos demonstra que vivam o problema do seguinte modo: "Acreditavam que a competitividade excessiva induzia a atuaçāo para impressionar as condutas próprias dos jogadores, rupturas de comunicaçōes, extravios do cgo, manobras políticas e, em casos extremos, ainda sabotagem. Liles explicitaram que o excesso de conflitos em suas filas é um fato muito comum, e que um gerente pode se comaranhar em dedicar mais tempo para tratar de ganhar ou defender-se do que para melhorar a produtividade" (Clinton 0. longenecker. Dennis $A$ Gioia. Diez mitos de la conduccion de gerentes. Alta Geréncia, Buenos Aires, marco, 1992, $N^{\circ} 6$ ). 
para que os recursos humanos da onganizaçāo respondam individualmente, criativamente, a um meio que requer adaptaçōes permanentes. Facilitar espaços. f́: a mesma idéia de Atenas, onde os grupos possam contestar a partir das condições particulares.

A última resposta a necessidade de levar a sua máxima expressão, a flexibilidade nas organizaçōes consiste na idéia da organização virtual. Seguindo-lhe, produzem-se combinaçōes de um número amplo de organizaçōes situadas em diversos países, para aproveitar oportunidades de mercado ou somar recursos para gerar produtos tecnológicos inovadores. Fissa organizaçāo virtual é transitória e desaparece ao cumprir-se o objetivo de sua criação ${ }^{17}$.

\section{3 - A revalorização do pessoal}

As evidências de toda ordem indicam que neste mundo de complexidade e incerteza, sem as pessoas nenhuma organização irá longe. A chave está, mais que nunca, no pessoal, em sua motivaçāo, $\mathrm{cm}$ sua capacidade de entender a realidade, de adaptar, de criar, de inovar.

A Universidade de Columbia, nos Fstados Unidos, c Korn Ferry Internacional, uma das principais agências de seleção de executivos do mundo inteiro, realizaram uma pesquisa com 1500 executivos de 20 países para determinar o perfil do gerente do ano $2000 \mathrm{c}$ selecionar pessoal com base nesse perfil. No perfil determinado aparecem em primeiro lugar três qualidades. O gerente que vão eleger será um que saiba gerenciar complexidade, que seja um bom negociador, e que tenha um desenvolvimento muito importante de liderança c orientação de recursos humanos. Os recursos humanos estão absolutamente num lugar central.

A Price Waterhouse realizou uma pesquisa, cm 1990, entre 6000 empresas curopéias e americanas para ver quais eram as práticas de pessoal nas empresas privadas.

O ponto central é de mudanças absolutamentc fundamentais no mancjo dos recursos humanos. Os que não fazcm essas mudanças ficam para trás totalmente. O trabalho conclui que toda organização empresarial que descuida das relaçöes bumanas está condenada ao fracasso ou à mediocridade. As mudanças sâo tâo radicais que Price Watcrhousc assinala nos resultados da pesquisa, por exemplo, que uma tendência modema crescente é a de climinar a comunicação por memorandos nas organizações modemas c

- John A. Byrne. The virtual corporation. International Business Week, 8 de Fevereiro de 1993. 
substituí-las pelo contato oral. Este, e nāo o formal memorando, é o melhor moxlo de comunicarse nas onganizaçōes, porque há feed-back, porque há interação, porque há criatividade, porque estabelece laços, enquanto que o outro bloqueia, incomunica. Necessitam-se novos tipos de liderança de pessoal cuja base principal há de ser a participação. A fórmula milenar de LAO 'TSE parece ter plena aplicação $\mathrm{cm}$ nosso tempo:

- O dirigente malvado é aquele a quem as pessoas desprezam.

- O bom dirigente é aquele a quem as pessoas reverenciam.

- O grande dirigente é aquele que faz as pessoas dizerem: nós mesmos ofizemos.

\section{4 - Renovação na formação de gerentes}

'Todo este conjunto de mudanças está determinando, finalmentc, variaçōes transcendentais em como se formam e se preparam gerentes. Uma investigação publicada em Fortune mostra evidências surpreendentes ${ }^{18}$. Os $50 \%$ dos egressos de boas escolas de Business Administrations nos Estados Unidos estão desempregados. Não tem onde colocar-se, ao contrário do que ocorria em outra década, onde as empresas iam às universidades buscá-Ios.
As empresas, frente ao desajuste entre a preparaçāo dos egressos e as necessidades da complexidade, da incerteza, da grande aldeia, optaram por tratar de formar seus próprios recursos, c há crescente competição entre planos de formação das empresas c o trabalho das Universidades. Frente a estes resultados algumas das principais Escolas de Business Administration dos Istados Unidos estão atualmente modiftcando totalmente o currículo.

Assim, por exemplo, a Escola de Wharton da Universidade de Pennsylvania, uma das primeiras do ranking, modificou todo o currículo de estudos em Business Administration. O novo gerente que vão formar para o sćculo XXI se orientará por: dar maior ênfase a habilidades para tratar com as pessoas; ter uma perspectiva mais global; desenvolver suas capacidades de criatividade e inovação; promover a solução de problemas no mundo real; c examinar os problemas das empresas desde o ponto de vista interdisciplinário.

O estudo da revista Fortune assinala que há um dicficit expressivo entre o que as escolas davam e o que as empresas solicitam, cm termos de Soft Skills. Habilidades em tecnologias leves, como estas introduzidas em Wharton. Numa frase bem lapidar, assinala que com as iscolas

10 - Alan Deutsdrman. The Trouble with MBAs. Fortune, 29 de julho de 1991. 
de Business Administration dos Estados Unidos aconteceu o mesmo que com boa parte da indústria norte-amcricana, ou seja, perdeu competitividade por não adaptar-se aos novos tempos.

Sobre o gerente público necessário

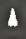

pós caracterizar o contexto dos anos 90, vimos novas demandas gerenciais para o gerente público. Num momento posterior, $a$ insuficiência do paradigma tradicional em gerência para responder as atuais demandas gerenciais. I:m outro momento, muito rapidamente, novas linhas de reflexão neste campo e desenvolvimentos tecnológicos renovadores que, poderiam ter múltiplas aplicações $\mathrm{cm}$ gerência pública. Num mundo onde, como disse Morin, a incerteza se instalou, daqui para adiante, com altas flutuações econômicas, com competitividade crescente, com dificuldades sociais muito signifcativas, com objetivos muito esperançosos de processos de democratizaçāo aprofundados, requerir-se-a uma estratćgia, diferente totalmente de outros tempos. Um Estado não patcrnalista, mas como se viu anteriormente, mais in teligente no que se refere ao estratégico.
Isto nāo se pode levar adiante senão com gerência pública de primcira qualidade. Im suma, através da gerência se implementarão ou se frustraño as políticas melhor desenhadas, os objetivos mais interessantes, tanto no campo da política cconômica como no campo da política social.

Não há nenhuma rayâo para pensar que no setor público não pode haver gerência da melhor qualidade. A excelência gerencial tem a ver com todas as outras coisas antes referidas, com os modelos organizacionais, com as tccnologias utilizadas, com o tipo de treinamento dos gerentes, e não é patrimônio de ninguém.

O desafio está em se adequar as organizaçōes públicas para lograr excelência. Obtê-lo requer, junto as modemiyaçōes tecnologicas, resgatar a noção de serviço público com suas conseqüentes implicaçōes em termos de honestidade na função. Estar no setor público e estar servindo a sociedade é tratar de contribuir para o bem estar coletivo. Sir Douglas Wass, que foi durante várias décadas, Dirctor do Serviço Civil de Inglaterra, em suas memórias chama poderosamente a atenção, de como apesar das frustrações, desencantos, decepções, $e$ da dureza da vida burocrática, 
sobrevive $e$ florece nos funcionários, o desejo de servir genuinamente ao público ${ }^{19}$, como o desafio, que significa servir a comunidade, pode sobreviver, todavia nessas condições.

Esssa possibilidade, a vocação ao serviço, teria que emoldurar tudo o que se faça sobre gerência no sctor público. Numa vocação de serviço, com instrumental moderno adaptado as especificidades da gerência pública $\mathrm{e}$ as novas demandas estão as melhores possibilidades de ajudar a solucionar aos graves problemas da América Latina e servir bem aos cidadãos.

\section{Resumen}

UNA GERENCIA PUBLICA PARA

\section{LOS NUEVOS TIEMPOS}

Una idea fundamental en gerencia en la actualidad es la que exprime que el pasado es una mala guia, porque, debido a las transformaciones aceleradas, el presente difiere del pasado y el futuro difcrirá aún más del presente. Como trabajar en este ámbito de cambios de los tiempos y de los cambios de los protagonistas? Desde ahora es necesario que las organizaciones públicas sutilicen sus mecanismos de interpretación de la realidad y sus capacidades de ajuste adaptativo a la misma.

\section{Abstract \\ PUBLIC MANAGEMENT FOR A NEW ERA}

The rate of change in management is so accelarated nowadays that the past is no longer a good reference in the area. How can we then proceed in these times of change? 'The public organizations must amend their ways of interpreting reality and their ability to adjust themselves to it.

Bernardo Kliksberg é diretor do Projeto Regional das Naçóes Unidas de Modernizaçáo do Estado (PNUD/CIAD).

Marcelo Brito é técnico da Dirctoria de İnsino e Pesquisas da INAPP

19 - Sir I)ougla Wass. The public service in modern socicty. Public Administration. Royal lnstitute of Public Administration, vol. 61, num 1, primavera de 1983, londres. 